EXTENDED REPORT

\title{
Clinical comorbidity in patients with osteoarthritis: a case- control study of general practice consulters in England and Wales
}

\author{
U T Kadam, K Jordan, P R Croft
}

Ann Rheum Dis 2004;63:408-414. doi: 10.1136/ard.2003.007526

See end of article for authors' affiliations ..........................

Correspondence to: Dr U T Kadam, Primary Care Sciences Research Centre, Keele University, Staffordshire ST5 5BG, UK; u.kadam@cphc. keele.ac.uk

Accepted 27 May 2003

\begin{abstract}
Objectives: To determine patterns of clinical comorbidity in general practice consulters with OA and compare them with comorbidity in consulters without $O A$.

Methods: A case-control study nested in a one-year prevalence survey of consultations in 60 general practices in England and Wales. Cases were 11375 subjects aged 50 and over who had consulted with OA during the study year. Controls were 11780 subjects matched for age and sex who had consulted during the study year, but not for OA. Morbidity outcomes were based on a standard clinical classification system.

Results: After adjusting for age, sex, and social class, cases were significantly more likely to have high levels of comorbidity than controls $(2.35 ; 2.16$ to 2.55). Significant OA comorbid associations with other musculoskeletal conditions included arthropathies (OR 2.26; $99 \% \mathrm{Cl} 1.50$ to 3.41), upper limb sprain (2.04; 1.38 to 3.00$)$, synovial and tendon disorders (2.03; 1.54 to 2.68$)$, and other joint disorders (2.00; 1.71 to 2.32$)$. OA non-musculoskeletal associations were with obesity $(2.25 ; 1.73$ to 2.92$)$, gastritis (1.98; 1.46 to 2.68$)$, phlebitis ( $1.80 ; 1.28$ to 2.52$)$, diaphragmatic hernia ( $1.80 ; 1.29$ to 2.51 ), ischaemic heart disease (1.73; 1.13 to 2.66 ) and intestinal diverticula (1.63; 1.20 to 2.23 ).

Conclusions: Comorbidity for OA was extensive, with musculoskeletal as well as non-musculoskeletal conditions. Age, sex, and social class did not explain this comorbidity but propensity to consult may be a part explanation. An important question remains as to whether comorbidity in general practice significantly adds to the disability or further impairs the health of patients with OA.
\end{abstract}

$\mathrm{T}$ he clinical records in a general practice are a source of population based data on all morbidity for which consultation is sought among its registered patients. There is widespread use of computers to record clinical contacts, interventions, and management among general practices in the United Kingdom, and clinical records have been used to study health needs, health interventions, and health outcomes for individual diseases such as ischaemic heart disease and diabetes mellitus. ${ }^{12}$ The clinical contacts may be for many different problems that a patient may present to the general practitioner and such records of contact offer potential insight into co-occurrence of multiple problems. The coexistence of other conditions with a defined index condition was originally defined as comorbidity by Feinstein. ${ }^{3}$ Presentation of problems, particularly in relation to specific chronic diseases, has been examined in general practice, ${ }^{45}$ but whether these comorbidities are conditionspecific according to the original Feinstein definition and how comorbidities other than specified chronic conditions are associated with an index condition, are questions which remain to be answered.

Osteoarthritis (OA) is one of the commonest morbidities in older people ${ }^{6}$ and the most common reason for restricted activity in their daily life. ${ }^{7}$ It has a high impact on healthcare use and costs, ${ }^{68}$ both in hospital (for example, joint replacements ${ }^{9}$ ) and primary care (for example, consultations ${ }^{10}$ and drug use ${ }^{11}$ ). It is a particularly important public health problem in an aging population. The prevalence of many other disabling conditions also rises with age, and some common chronic conditions can be found alongside OA. ${ }^{12}$ It is not known, however, if there is comorbidity specific to patients with OA in general practice or how such comorbidity might contribute to the overall impact of an individual condition such as OA on the healthcare services.
We therefore used a large database of general practice records to describe the prevalence and patterns of clinical comorbidity using the index condition of OA. As the first phase in an investigation of OA comorbidity, our study investigated the prevalence of multiple clinical problems in patients with OA compared with controls matched for age and sex in a national population of primary care consulters.

\section{METHOD \\ Morbidity Statistics in General Practice (MSGP) database}

The MSGP is an anonymised database of computerised patient records collected as part of a national morbidity survey of primary care consultations in the UK. Since the 1950s there have been four such surveys, each lasting for 1 year. For this study we used the most recent survey (MSGP4), which took place between 1 September 1991 and 31 August 1992. ${ }^{13}$ All doctors and nurses employed in the 60 study practices in England and Wales recorded every face to face contact with patients on their practice register. The UK Office of Population and Census Surveys, the Royal College of General Practitioners, and the Department of Health collaborated to carry out the survey. The database comprised 142507 patients aged 50 years and over, of whom 112116 (78.7\%) had consulted at least once during the study year. Previous studies have validated the MSGP4 database as a complete record of consultations in the participating practices and it is used as a reference standard for other consultation databases in the United Kingdom. ${ }^{14-16}$

\section{MSGP4 demographic data}

In addition to clinical contacts, the database also contains records of age, sex, and social class. Social class was measured by a national standard occupational classification 
system which uses five groups: socioeconomic class (SEC) I (professional), SEC II (managerial and technical), SEC IIIN (skilled non-manual), SEC IIIM (skilled manual), SEC IV (partly skilled), and SEC V (unskilled) ${ }^{17}$; socioeconomic information was available for $83 \%$ of the database population. Comparison of this database population with the 1991 census data for England and Wales suggested that it was broadly representative of the national population. ${ }^{13}$

\section{Morbidity classification in MSGP4}

The practices entered on computer one or more morbidity codes for each consultation during the survey year. The codes are derived from a system of clinical classification used in the UK, the Read code classification. The UK Department of Health has adopted this as the standard for recording clinical information in the National Health Service. ${ }^{18}$ Clinical information is grouped into broad categories ("main body system chapters"), designated by letter, and every chapter incorporates four numbered hierarchical levels, each providing progressively finer diagnostic detail. Figure 1 shows examples of this within the musculoskeletal chapter.

\section{Study design}

We carried out a case-control study, using the MSGP4 database of coded consultations as the measures of clinical comorbidity, selecting an index population of OA consulters as cases and those without an OA consultation as controls.

\section{Study population}

Case definition of "OA" was based on all diagnoses at the third level of the musculoskeletal and connective disease Read chapter-namely, "OA and allied disorders". All patients aged 50 and over who had consulted for OA at least once during the MSGP4 survey year $(n=12885)$ formed the cases, and represented $11.5 \%$ of the consulting population. The control group consisted of the same number of subjects randomly selected from the population of consulters aged 50 and over who had no record of OA, after frequency matching to the cases by sex and four age groups: $50-64$ years, 65-74 years, 75-84 years, and 85 years and over. The random selection was performed using SPSS. ${ }^{19}$ Patients who had been registered with the survey practices for less than the full 366 days were then excluded $(727(5.6 \%)$ cases and 1105 $(8.6 \%)$ controls), and this reduced the numbers to 12158 cases and 11780 controls.

This is a study of OA comorbidity, using the concept of comorbidity as proposed by Feinstein ${ }^{3}$-namely, the presence of other clinical conditions with an index condition (OA in this study). Our cases therefore were designed to provide an estimate of the "likelihood of consultation for morbidities

\begin{tabular}{|c|c|c|}
\hline First Read level & Chapter N & $\begin{array}{l}\text { Musculoskeletal and } \\
\text { connective tissue diseases }\end{array}$ \\
\hline $\begin{array}{l}\text { Second level } \\
6 \text { subgroups }\end{array}$ & NO & $\begin{array}{l}\text { Arthropathies and related } \\
\text { disease }\end{array}$ \\
\hline $\begin{array}{l}\text { Third level } \\
13 \text { subgroups }\end{array}$ & N05 & $\begin{array}{l}\text { Osteoarthritis and allied } \\
\text { disorders }\end{array}$ \\
\hline $\begin{array}{l}\text { Fourth level } \\
7 \text { subgroups }\end{array}$ & N050 & Generalised osteoarthritis \\
\hline $\begin{array}{l}\text { Fifth level } \\
10 \text { subgroups }\end{array}$ & N0501 & $\begin{array}{l}\text { Generalised osteoarthritis } \\
\text { of hand }\end{array}$ \\
\hline
\end{tabular}

Figure 1 An illustration of the Read code hierarchy using the example of "Musculoskeletal and connective tissue disorders" chapter. other than OA" among OA consulters; the controls provide estimates of the "likelihood of consultation for morbidities other than $\mathrm{OA}^{\prime \prime}$ among non-OA consulters of comparable age and sex to the cases. We therefore excluded subjects from our case group who had consulted only for OA and nothing else in the study year; this made our cases comparable with the control group, all of whom had consulted at least once in the study year for a morbidity other than OA. This resulted in exclusion of a further 783 cases, leaving 11375 cases available for the analysis.

\section{Morbidity definitions}

The comorbid effect of OA was measured by the difference in the prevalence of morbidities other than OA in cases compared with controls during the whole study year. For the purposes of our study we used two levels of the Read hierarchy to classify morbidities. Firstly, all morbidity data were collated at the first (main body system chapter) level and referred to as "broad disease groups". Secondly, morbidity data were collated at the third level and referred to here as "specific disease groups".

Morbidity prevalence did not include repeat consultations for the same morbidity in the study year, and we defined it in two ways. Firstly, it was defined by morbidity count-based on simple numerical counts of coexisting specific disease groups. To assess morbidity count in the case group, our hypothesis was that there was no difference in the morbidity counts in the case group compared with the control group. Thus the case and control groups were defined in four categories of morbidity counts: single morbidity; two or three morbidities; four or five morbidities; and six or more morbidities. Secondly, it was defined by clinical morbidity-based on OA combinations with (a) broad disease groups and $(b)$ specific disease groups. To assess clinical morbidity, we employed the null hypothesis that stated there is no difference between the case and control groups in the occurrence of a specific stated morbidity.

\section{Morbidity outcomes}

Over 10000 individual Read codes had been used in the MSGP4 database, hence our decision to collate all consultations at two levels of the Read system, the first and the third. The clinical morbidities described relate to at least one consultation for the Read code category during the study year; repeat consultations within the same category are not included. Specific disease groups were also categorised into musculoskeletal disorders and non-musculoskeletal disorders.

\section{Statistical analysis}

The comorbid effect of OA was first estimated by comparing the morbidity count in cases and controls. The effects of age, sex, and social class on the morbidity count were estimated by logistic regression, summarised using odds ratios with 95\% confidence intervals. The comorbid effect was then further explored by estimating associations of OA with other specific morbidities: odds ratios adjusted for age, sex, and social class, were calculated for $(a)$ broad disease groups (16 in total), (b) specific disease groups of musculoskeletal disorders, and (c) specific disease groups of non-musculoskeletal conditions. After applying the selection criterion of a minimum prevalence for each of these groups of $0.5 \%$ in the study population, there were 134 specific disease groups for which consultation had been sought by cases during the survey year. Case-control associations with these 134 morbidities were examined by unconditional logistic regression using $99 \%$ confidence intervals for the odds ratios to give more stringent results. It is known that some patients present many problems to health care and appear to have a 
propensity to consult given a health problem. ${ }^{20}$ Thus, possibly, any potential associations between OA and other morbidities may reflect this propensity. Because there is no standard measure of "propensity" we assessed the effect of this issue in two ways: (a) odds ratios for a broad disease outcome were also adjusted for the number of other broad disease group consultations by the same person and $(b)$ odds ratios for a specific disease group were adjusted by the category of morbidity count, as defined above in the morbidity definitions, again using 99\% confidence intervals for the odds ratios. All analyses were carried out using SPSS version 10.0 for Windows. ${ }^{19}$

\section{RESULTS}

\section{Morbidity count}

The prevalence of a high morbidity count (six or more conditions other than OA) was greater $(31 \%)$ in cases than in controls $(21 \%)$. In cases, a high morbidity count was more common in women (33\%) than men (26\%) (difference $=7.6 \%$; $95 \%$ confidence interval (CI) 5.8 to 9.3 ), in those aged 75 and over compared with the youngest group (5.9; 2.4 to 9.6), and in socioeconomic groups IV and V (33\%) compared with professional and managerial groups $(29 \%)$ (3.4; 0.9 to 5.9). Age, sex, and socioeconomic variations in morbidity count were similar among controls but less marked (table 1). In the case-control analysis, after adjusting for age, sex, and social class, cases were significantly more likely to have medium $(1.81 ; 95 \%$ CI 1.66 to 1.97$)$ and high $(2.35 ; 2.16$ to 2.55 ) levels of morbidity counts than controls (table 2 ).

\section{Clinical morbidity other than OA: broad disease groups}

Cases were more likely than controls to have consulted within all of the 16 broad disease chapters, with the exception of infectious disease, neoplasms, and congenital anomalies chapters (table 3 ). The strongest association of OA was with other consultations in the musculoskeletal and connective tissue disease chapter (OR 1.80, 99\% CI 1.67 to 1.94) having adjusted for age, sex, and social class. Other strong associations with OA were with digestive system disorders and injury. The weakest significant association was with respiratory disorders ( $1.13 ; 1.05$ to 1.21$)$. After adjusting for the number of other broad disease chapters for which each subject had consulted in the study year, most of these associations became weaker, but eight remained significant $(p<0.01)$. The two strongest associations in the OA case group compared with controls after this adjustment were for musculoskeletal and connective tissue diseases ( $1.73 ; 1.60$ to $1.86)$, and digestive system diseases ( $1.33 ; 1.21$ to 1.45$)$.

\section{Clinical morbidity: musculoskeletal disorders}

The most prevalent musculoskeletal conditions were back disorders (cases $8.5 \% v$ controls $6.2 \%$ ), other joint disorders $(7.7 \vee 4.0)$, soft tissue disorders $(7.0 \vee 4.0)$, peripheral enthesopathies $(5.4 \quad v \quad 3.5)$, and spondylosis (5.8 $v 3.1)$ (table 4). Of the 23 musculoskeletal specific disease groups, 11 were significantly more prevalent in cases than in controls. The most significant associations with OA after adjusting for age, sex, and social class were with other arthropathies (OR 2.26 ; $99 \%$ CI 1.50 to 3.41$)$, upper limb sprain $(2.04 ; 1.38$ to $3.00)$, synovial and tendon disorders (2.03; 1.54 to 2.68$)$, and other joint disorders $(2.00 ; 1.71$ to 2.32$)$ (table 4$)$. Even after adjusting for morbidity count (that is, the number of other specific disease categories for which each subject had consulted in the study year), all significant associations between musculoskeletal specific disease categories and OA remained statistically significant, although weaker.

\section{Clinical morbidity: non-musculoskeletal disorders}

The most common non-musculoskeletal conditions for which consultation was sought (cases $v$ controls) were bronchitis $(15.0 \% \vee 13.3 \%)$, accidental injury (13.3 $v 10.4)$, general symptoms (7.5 $v 6.0)$, neurotic disorders (7.1 $v 6.1)$, and urinary tract disorders $(6.3 v 4.8)$. There was a wide range of associations of $\mathrm{OA}$ with specific disease groups. Table 5 presents the 44 significant associations out of 111 specific disease categories that were examined in descending order of strength of association. The strongest associations between $\mathrm{OA}$ and non-musculoskeletal conditions after adjusting for age, sex, and social class were with obesity (OR 2.25; 99\% CI 1.73 to 2.92 ), gastritis (1.98; 1.46 to 2.68 ), phlebitis (1.80; 1.28 to 2.52$)$, diaphragmatic hernia $(1.80 ; 1.28$ to 2.52$)$, ischaemic heart disease (1.73; 1.13 to 2.66 ), cellulitis (1.67; 1.14 to 2.43 ), and intestinal diverticula (1.63; 1.20 to 2.23 ). Other notable but weaker associations of the OA case group were with depressive disorder ( $1.45 ; 1.15$ to 1.82 ), falls (1.40; 1.13 to 1.73$)$, and accidental injury ( $1.32 ; 1.18$ to 1.46$)$. After adjusting for morbidity count (that is, the number of other specific disease categories for which each subject had consulted in the study year), 17 significant associations remained between $\mathrm{OA}$ and specific non-musculoskeletal disease groups (results not shown but these 17 categories are marked $†$ in table 5). The strongest associations with OA, after adjusting for age, sex, deprivation, and morbidity count,

Table 1 Specific disease morbidity counts by age, sex, and social class for cases and control groups

\begin{tabular}{|c|c|c|c|c|c|c|c|c|}
\hline & \multicolumn{4}{|c|}{ OA cases $(n=11375)$} & \multicolumn{4}{|c|}{ Non-OA controls $(n=11780$ ) } \\
\hline & Single & $\begin{array}{l}\text { Low } \\
\text { ( } 2 \text { or } 3)\end{array}$ & $\begin{array}{l}\text { Medium } \\
\text { (4 or } 5)\end{array}$ & $\begin{array}{l}\text { High } \\
\text { ( } 6 \text { or more) }\end{array}$ & Single & $\begin{array}{l}\text { Low } \\
\text { ( } 2 \text { or } 3)\end{array}$ & $\begin{array}{l}\text { Medium } \\
\text { (4 or } 5 \text { ) }\end{array}$ & $\begin{array}{l}\text { High } \\
\text { ( } 6 \text { or more) }\end{array}$ \\
\hline \multicolumn{9}{|l|}{ Sex } \\
\hline Male & 612 (16) & 1305 (33) & 988 (25) & $1015(26)$ & 972 (24) & 1571 (38) & $877(21)$ & 698 (17) \\
\hline Female & 865 (12) & $2173(29)$ & $1922(26)$ & 2495 (33) & 1493 (19) & 2661 (35) & $1766(23)$ & $1742(23)$ \\
\hline \multicolumn{9}{|l|}{ Age } \\
\hline $50-64$ & 595 (14) & $1347(32)$ & 1075 (25) & 1241 (29) & $1074(24)$ & 1677 (37) & $952(21)$ & 801 (18) \\
\hline $65-74$ & 479 (14) & 1091 (31) & 889 (25) & 1057 (30) & 781 (21) & $1327(36)$ & 857 (23) & 743 (20) \\
\hline $75-84$ & 329 (12) & $812(29)$ & $730(26)$ & 932 (33) & 471 (17) & 968 (34) & $656(23)$ & 721 (26) \\
\hline $85+$ & $74(9)$ & 228 (29) & 216 (27) & 280 (35) & 139 (18) & 260 (35) & $178(24)$ & 175 (23) \\
\hline \multicolumn{9}{|l|}{ Social class } \\
\hline I/II & 325 (14) & 750 (32) & $591(25)$ & $692(29)$ & $650(22)$ & 1093 (37) & $687(23)$ & $552(18)$ \\
\hline IIIN/M & 589 (13) & 1444 (31) & $1182(25)$ & 1426 (31) & 885 (19) & $1633(36)$ & $1045(23)$ & $1016(22)$ \\
\hline IV/V & 355 (12) & $827(28)$ & 774 (27) & 951 (33) & $493(20)$ & 857 (35) & 561 (22) & $565(23)$ \\
\hline Other & 94 (10) & $262(30)$ & $223(26)$ & 295 (34) & 167 (19) & $320(36)$ & 201 (23) & 199 (22) \\
\hline Unknown & 114 (19) & 195 (33) & 140 (23) & $146(25)$ & 270 (32) & 329 (38) & 149 (17) & 108 (13) \\
\hline Total & 1477 (13) & $3478(30)$ & $2910(26)$ & 3510 (31) & 2465 (21) & $4232(36)$ & $2643(22)$ & $2440(21)$ \\
\hline
\end{tabular}


Table 2 Specific disease morbidity counts compared between case and control groups

\begin{tabular}{|c|c|c|c|c|}
\hline Morbidity count & $\begin{array}{l}\text { OA cases } \\
\text { No }(\%)\end{array}$ & $\begin{array}{l}\text { Non-OA controls } \\
\text { No }(\%)\end{array}$ & $\begin{array}{l}\text { Unadjusted } \\
\text { OR (95\% CI) }\end{array}$ & $\begin{array}{l}\text { Adjusted } \\
\left.\text { OR* }^{*} 95 \% \mathrm{Cl}\right)\end{array}$ \\
\hline Single & 1477 (13) & $2465(21)$ & 1.00 & 1.00 \\
\hline Low (2 or 3 ) & 3478 (30) & $4232(36)$ & 1.37 (1.27 to 1.48 ) & 1.36 (1.26 to 1.47$)$ \\
\hline Medium (4 or 5 ) & $2910(26)$ & $2643(22)$ & 1.84 (1.69 to 2.00$)$ & 1.81 (1.66 to 1.97$)$ \\
\hline High (6 or more) & $3510(31)$ & $2440(21)$ & $2.40(2.11$ to 2.61$)$ & 2.35 (2.16 to 2.55$)$ \\
\hline
\end{tabular}

were for obesity $(2.15 ; 1.65$ to 2.80$)$, gastritis $(1.72 ; 1.26$ to 2.33 ), and phlebitis ( $1.62 ; 1.15$ to 2.28 ).

\section{DISCUSSION}

In our population based study of general practice consulters aged 50 and over followed up for one year, $11.5 \%$ had consulted for the index condition of OA. In this OA group $31 \%$ had consulted for five or more other clinical conditions during the course of the year; the comparable figure for the non-OA population was $21 \%$. High morbidity counts were associated with being female, older, and of unskilled or partly skilled socioeconomic status, but these factors did not explain the higher counts in the patients with OA compared with the non-OA controls.

OA consulters were more likely than the controls to have other generalised and localised musculoskeletal problems or be injured in a 12 month period. These results are consistent with evidence that patients presenting with single joint $\mathrm{OA}$ are more likely to have OA or related symptoms in other joints, ${ }^{21}{ }^{22}$ that soft tissue disorders contribute both to the development of OA and to the pain and restricted movement in $\mathrm{OA}^{23}{ }^{24}$ and that patients with OA are more prone to falls and injury. ${ }^{25}$ However, there may be another explanation for some of this musculoskeletal comorbidity. Although the MSGP database was specifically set up to collect morbidity data in general practice using a standard clinical classification system, there was no standardisation of how general practitioners would apply the codes. Diagnosis in primary care has to take account of the undifferentiated and vague way in which symptoms often present. The case group was identified by the term "OA", as used by general practitioners in every day clinical contact. This label possesses face validity for general practice, but may differ from a diagnosis based on criteria such as radiological changes in OA. ${ }^{26}$ For the purposes of the study we have assumed that it represents symptoms suggestive of OA to the general practitioner. Although labels such as "arthropathies" and "arthralgia" might represent distinctive and additional problems to OA, it is also quite plausible that they represent earlier stages of OA before the diagnosis is applied. For example "knee joint pain" may be recorded on the first visit, but "OA" is applied later after an $x$ ray examination. Furthermore, once a musculoskeletal diagnosis is given, both patients and their general practitioners may pay more attention to the presence of other musculoskeletal disorders, so that in effect patients with OA were "screened" for these other conditions. The musculoskeletal morbidity we have observed in patients with OAparticularly undifferentiated joint pain-would then in part represent overlap between labels and the way they are applied at different times as a clinical syndrome develops in general practice.

Comorbidity of OA with selected chronic conditions other than musculoskeletal disorders has been shown previously. Hospital based studies in America have shown that peptic ulcer disease and renal disease ${ }^{27}$ are associated with OA and, in general practice based studies in Holland, that chronic conditions such as diabetes, heart disease, and OA often occur together. ${ }^{4}$ The explanation for specific comorbidity may lie in shared mechanisms of disease or the impact which one condition may have on increasing vulnerability to another. Previous research has suggested that patients with OA have reduced cardiovascular fitness. ${ }^{28}$ The association of depression and obesity with chronic joint pain and OA is well reported in population based studies. ${ }^{29}{ }^{30}$ The finding that gastrointestinal consultations are more prevalent in those with OA is plausibly explained by use of non-steroidal antiinflammatory drugs for musculoskeletal pain in primary care. ${ }^{31}$ With respect to the reasons for this, it is important to consider whether comorbid conditions might be clinically or pathologically related to the syndrome of OA or whether bias

Table 3 Clinical morbidity other than OA, classified by the main Read code chapters compared between case and control groups

\begin{tabular}{|c|c|c|c|c|c|}
\hline \multicolumn{2}{|c|}{ Read chapter description } & \multirow{2}{*}{$\begin{array}{l}\text { OA cases } \\
\text { No }(\%) \\
1248(11.0)\end{array}$} & \multirow{2}{*}{$\begin{array}{l}\text { Non-OA controls } \\
\text { No (\%) }\end{array}$} & \multirow{2}{*}{$\frac{O^{*}(99 \% \mathrm{Cl})}{1.11(0.99 \text { to } 1.24)}$} & \multirow{2}{*}{$\frac{\text { ORt }(99 \% \mathrm{Cl})}{1.00(0.89 \text { to } 1.12)}$} \\
\hline$A$ & Infectious and parasitic diseases & & & & \\
\hline B & Neoplasms & $517(4.5)$ & $547(4.6)$ & $0.98(0.83$ to 1.16$)$ & $0.92(0.78$ to 1.09$)$ \\
\hline C & Endocrine disorders & 1393 (12.2) & $1188(10.1)$ & 1.23 (1.11 to 1.38$)$ & 1.18 (1.06 to 1.32 ) \\
\hline D & Haematological diseases & $345(3.0)$ & 279 (2.4) & 1.27 (1.03 to 1.57$)$ & 1.15 (0.93 to 1.43$)$ \\
\hline $\mathrm{E}$ & Mental disorders & $1680(14.8)$ & $1512(12.8)$ & 1.16 (1.05 to 1.28$)$ & $1.04(0.94$ to 1.15$)$ \\
\hline $\mathrm{F}$ & Central nervous system disorders & $3146(27.7)$ & $2910(24.7)$ & $1.16(1.07$ to 1.25$)$ & 1.10 (1.02 to 1.19$)$ \\
\hline G & Circulatory system diseases & $4109(36.1)$ & $3704(31.4)$ & 1.22 (1.13 to 1.31$)$ & 1.19 (1.11 to 1.28$)$ \\
\hline $\mathrm{H}$ & Respiratory system diseases & $4143(36.4)$ & 3932 (33.4) & $1.13(1.05$ to 1.21$)$ & 1.07 (0.99 to 1.15$)$ \\
\hline J & Digestive system diseases & $2517(22.1)$ & $1890(16.0)$ & $1.47(1.35$ to 1.60$)$ & 1.33 (1.21 to 1.45$)$ \\
\hline K & Genitourinary system diseases & $1752(15.4)$ & 1587 (13.5) & 1.17 (1.06 to 1.29$)$ & 1.07 (0.97 to 1.19$)$ \\
\hline M & Skin and subcutaneous tissue diseases & $2293(20.2)$ & $1952(16.6)$ & $1.26(1.15$ to 1.38$)$ & $1.16(1.06$ to 1.27$)$ \\
\hline $\mathrm{N} \ddagger$ & Musculoskeletal and connective tissue diseases & $4099(36.0)$ & $2795(23.7)$ & 1.80 (1.67 to 1.94$)$ & $1.73(1.60$ to 1.86$)$ \\
\hline$P^{+}$ & Congenital anomalies & $79(0.7)$ & $77(0.7)$ & $1.06(0.70$ to 1.61$)$ & 0.97 (0.64 to 1.48 ) \\
\hline R & Symptoms and signs & $3050(26.8)$ & $2533(21.5)$ & 1.32 (1.22 to 1.43$)$ & 1.18 (1.08 to 1.28$)$ \\
\hline S & Injury and poisoning & $2608(22.9)$ & $2032(17.2)$ & $1.42(1.30$ to 1.54$)$ & 1.16 (1.06 to 1.27$)$ \\
\hline $\mathrm{T}$ & Causes of injury and poisoning & $2369(20.8)$ & $1896(16.1)$ & 1.36 (1.25 to 1.49$)$ & 1.09 (0.99 to 1.20$)$ \\
\hline
\end{tabular}

Bold indicates statistically significant at $1 \%$ level.

*Adjusted for age, sex, and social class; non-OA group is reference group; tadjusted for age, sex, social class, and number of other broad disease groups for which subjects consulted; non-OA group is reference group; fexcluding N05. 
Table 4 Clinical morbidity for musculoskeletal disorders by case and control groups

\begin{tabular}{|c|c|c|c|}
\hline Morbidity (Read code) & $\begin{array}{l}\text { OA cases } \\
\text { No (\%) }\end{array}$ & $\begin{array}{l}\text { Non-OA } \\
\text { controls } \\
\text { No }(\%)\end{array}$ & $O R^{*}(99 \% \mathrm{Cl})$ \\
\hline Rheumatoid arthritis and inflammatory disorders (N04) & $140(1.2)$ & $134(1.1)$ & $1.08(0.79$ to 1.47$)$ \\
\hline Other and unspecified arthropathies (N06) & $126(1.1)$ & $58(0.5)$ & $2.26(1.50$ to 3.41$)$ \\
\hline Other or unspecified joint disorders (N09) & $875(7.7)$ & $467(4.0)$ & 2.00 (1.71 to 2.32$)$ \\
\hline Spondylosis and allied disorders (N11) & $656(5.8)$ & $364(3.1)$ & 1.89 (1.59 to 2.25$)$ \\
\hline Intervertebral disc disorders (N12) & $104(0.9)$ & $78(0.7)$ & 1.37 (0.93 to 2.02$)$ \\
\hline Other cervical disorders (N13) & $143(1.3)$ & $144(1.2)$ & 1.01 (0.75 to 1.38$)$ \\
\hline Other and unspecified back disorders (N14) & $965(8.5)$ & $726(6.2)$ & 1.39 (1.22 to 1.59$)$ \\
\hline Polymyalgia rheumatica (N20) & $73(0.6)$ & $63(0.5)$ & $1.19(0.76$ to 1.86$)$ \\
\hline Peripheral enthesopathies and allied syndromes (N21) & $617(5.4)$ & $415(3.5)$ & 1.59 (1.35 to 1.89$)$ \\
\hline Synovial, tendon, or bursa disorder (N22) & $255(2.2)$ & $134(1.1)$ & 2.03 (1.54 to 2.68 ) \\
\hline Muscle, ligament, and fascia disorders (N23) & $128(1.1)$ & $101(0.9)$ & $1.31(0.93$ to 1.85$)$ \\
\hline Other soft tissue disorders (N24) & $791(7.0)$ & $467(4.0)$ & 1.78 (1.53 to 2.08$)$ \\
\hline Other bone or cartilage disorders (N33) & $135(1.2)$ & $88(0.7)$ & 1.57 (1.10 to 2.24$)$ \\
\hline Sprain of shoulder and upper arm (S50) & $129(1.1)$ & $68(0.6)$ & 2.04 (1.38 to 3.00$)$ \\
\hline Sprain of knee or leg (S54) & $159(1.4)$ & $97(0.8)$ & 1.73 (1.24 to 2.42 ) \\
\hline Sprain of ankle or foot (S55) & $136(1.2)$ & $116(1.0)$ & $1.21(0.87$ to 1.68$)$ \\
\hline Sprain of pelvic ligament (S56) & $76(0.7)$ & $68(0.6)$ & $1.13(0.73$ to 1.75$)$ \\
\hline Sprains of other parts of back (S57) & 218 (1.9) & $186(1.6)$ & $1.21(0.93$ to 1.57$)$ \\
\hline Other sprains and strains (S5y) & $94(0.8)$ & $75(0.6)$ & $1.30(0.87$ to 1.95$)$ \\
\hline Open wound of knee, leg, and ankle (SA1) & $75(0.7)$ & $70(0.6)$ & $1.11(0.72$ to 1.70$)$ \\
\hline Superficial injury of leg, excluding foot (SD6) & $79(0.7)$ & $94(0.8)$ & $0.84(0.57$ to 1.25$)$ \\
\hline Contusion, trunk (SE2) & $71(0.6)$ & $58(0.5)$ & 1.25 (0.79 to 1.97$)$ \\
\hline Contusion, leg and unspecified sites (SE4) & $152(1.3)$ & $83(0.7)$ & 1.87 (1.31 to 2.66$)$ \\
\hline
\end{tabular}

Bold indicates statistically significant at $1 \%$ level.

*Adjusted for age, sex, and social class; non-OA group is the reference group.

and confounding might explain the observations. This study therefore confirms some plausible chronic disease associations but adds a wider picture of other problems that appear to occur more commonly in patients consulting with OA and which are also presented to their general practitioners.

\section{Design issues}

We investigated OA under a broad definition. However, there is evidence that the course of the condition varies in different joints, ${ }^{32}$ and whether comorbidity also varies with joint site remains to be established.

Our study applied case-control comparisons by excluding 783 patients who had consulted only about OA in the study period. This was to ensure we were comparing the incidence of non-OA consultations in the presence and in the absence of OA. This conservative assumption was made in line with the concept of comorbidity as originally proposed by Feinstein ("other conditions in the presence of an index condition"). We did however reanalyse the dataset including the "OA consultation only" group. After adjustment for age, sex, and social class, minimal change in the measure of OA associations with specific disease groups was found. All the musculoskeletal associations shown in table 4 remained significant, as did all the non-musculoskeletal conditions highlighted in the text.

Subjects who were registered with their general practice for less than the full study year were excluded, because they would not have contributed to the full year's consultation count. If the reason for truncated registration was linked to comorbidity (for example, death), this might be a source of bias. However, the main reason for incomplete records in the study general practices was movement of patients to nonstudy practices, and it is unlikely that the small numbers excluded for this reason would bias the results.

Finally, our study describes the prevalence of comorbidity in one year. Some comorbidity might only arise across several years for a chronic disease such as OA. However, our study was based on a large sample of consulters and is likely to have given a good cross sectional representation of comorbid links, regardless of the time over which they might have developed. Furthermore, chronic conditions in general practice are likely to be recorded during any 12 month period, regardless of when they started, because of patterns of review and long term drug treatment. However, we accept that our "one year period prevalence of comorbidity" may underestimate the cumulative long term prevalence.

\section{General practice records as a measure of morbidity}

Two different types of explanation relate to the consultation process itself. One possibility is that frequent presentation provides the opportunity for general practitioners to detect more health problems (for example, heart disease or phlebitis). Another possibility is that comorbidity in primary care represents a propensity to seek health care more frequently for a range of symptoms. ${ }^{33}$ Such heightened symptom awareness, whatever its cause, seems to be a feature of patients with chronic widespread pain, ${ }^{34}$ but it has not been studied in older adults with multiple joint pains. We attempted to explore this issue by using the overall number of morbidities for which consultation was sought as a proxy measure of propensity to consult. The weaker but persisting associations after this crude adjustment suggest that there is some effect of propensity to consult on the associations found, but that it only partially explains our observations. Whatever the explanations, the fact remains that there are high levels of OA comorbidity with which patients present to general practice and which are likely to have a high impact on overall health status and healthcare resources.

The general practice database used for this study had collected information from 60 general practices across England and Wales. The population registered with these practices was representative of the England and Wales population and was unselected by health care or by membership of particular groups. Our morbidity measures relied on general practice consultations in this population and it is reasonable to assume that the data represent complete ascertainment of consultations within this population during the year of the survey. Morbidity based on consultations has to be interpreted according to the possible 
Table 5 Significant clinical morbidity for non-musculoskeletal disorders by case and control groups

\begin{tabular}{|c|c|c|c|}
\hline Morbidity (Read code) & $\begin{array}{l}\text { OA cases } \\
\text { No }(\%)\end{array}$ & $\begin{array}{l}\text { Non-OA controls } \\
\text { No }(\%)\end{array}$ & $\mathrm{OR}^{*}(99 \% \mathrm{Cl})$ \\
\hline Obesity and other disorders (C38) & $317(2.8)$ & $148(1.3)$ & $2.25(1.73$ to 2.92$) \dagger$ \\
\hline Gastritis and duodenitis (J15) & $214(1.9)$ & $113(1.0)$ & $1.98(1.46$ to 2.68$) \dagger$ \\
\hline Phlebitis and thrombophlebitis (G80) & $161(1.4)$ & $93(0.8)$ & $1.80(1.28$ to 2.52$) \dagger$ \\
\hline Diaphragmatic (hiatus) hernia (J34) & $167(1.5)$ & $95(0.8)$ & $1.80(1.29$ to 2.51$) \dagger$ \\
\hline Ischaemic heart disease (G3) & $97(0.9)$ & $58(0.5)$ & $1.73(1.13$ to 2.66$) \dagger$ \\
\hline Cellulitis and abscess of finger or toe (M02) & $124(1.1)$ & $76(0.6)$ & $1.67(1.14$ to 2.43$) \dagger$ \\
\hline Diverticula of intestine (J51) & $179(1.6)$ & $114(1.0)$ & $1.63(1.20$ to 2.23$) \dagger$ \\
\hline Other procedure complication (SP2) & $100(0.9)$ & $66(0.6)$ & 1.63 (1.08 to 2.45$)$ \\
\hline Lachrymal system disorders (F4F) & $174(1.5)$ & $112(1.0)$ & $1.61(1.18$ to 2.21$) \dagger$ \\
\hline Disorders of stomach function (J16) & $631(5.5)$ & 407 (3.5) & $1.61(1.36$ to 1.90$) \dagger$ \\
\hline Gout (C34) & $196(1.7)$ & $134(1.1)$ & $1.53(1.14$ to 2.05$) \dagger$ \\
\hline Acute respiratory infections $(\mathrm{HO}$.) & $190(1.7)$ & $126(1.1)$ & $1.53(1.13$ to 2.06$) \dagger$ \\
\hline Chronic pharyngitis and nasopharyngitis ( $\mathrm{H} 12)$ & $224(2.0)$ & $153(1.3)$ & $1.51(1.15$ to 1.99$) \dagger$ \\
\hline Chronic skin ulcer (M27) & $118(1.0)$ & $81(0.7)$ & 1.49 (1.02 to 2.17$)$ \\
\hline Urinary system symptoms (R08) & $234(2.1)$ & $163(1.4)$ & 1.48 (1.13 to 1.93$)$ \\
\hline Erythematosquamous dermatosis (M10) & $139(1.2)$ & $97(0.8)$ & 1.47 (1.04 to 2.08$)$ \\
\hline Depressive disorder (E2B) & $314(2.8)$ & $223(1.9)$ & 1.45 (1.15 to 1.82$)$ \\
\hline Varicose veins of the legs (G83) & $423(3.7)$ & $307(2.6)$ & $1.42(1.17$ to 1.73$) \dagger$ \\
\hline Dermatitis or other eczema (M12) & $327(2.9)$ & $239(2.0)$ & $1.42(1.14$ to 1.78$) \dagger$ \\
\hline Iron deficiency anaemia (DOO) & $186(1.6)$ & $134(1.1)$ & 1.41 (1.05 to 1.89$)$ \\
\hline Fall on same level (TC5) & 368 (3.2) & $267(2.3)$ & 1.40 (1.13 to 1.73$)$ \\
\hline Functional gastrointestinal disorders (J52) & $600(5.3)$ & $448(3.8)$ & 1.38 (1.17 to 1.63$)$ \\
\hline Symptoms affecting skin and other tissues (RO2) & $524(4.6)$ & 397 (3.4) & $1.37(1.15$ to 1.64$) \dagger$ \\
\hline Angina pectoris (G33) & $654(5.7)$ & 499 (4.2) & $1.36(1.16$ to 1.59$) \dagger$ \\
\hline Digestive system symptoms (R07) & $243(2.1)$ & $183(1.6)$ & 1.35 (1.04 to 1.74$)$ \\
\hline Adverse effects (SN5) & $596(5.2)$ & 459 (3.9) & 1.35 (1.14 to 1.59$)$ \\
\hline Erythematous conditions (M15) & $213(1.9)$ & $164(1.4)$ & 1.33 (1.01 to 1.74$)$ \\
\hline Peripheral vascular disease (G73) & 216 (1.9) & 168 (1.4) & 1.32 (1.01 to 1.72$)$ \\
\hline Diseases of oesophagus (J10) & 396 (3.5) & $309(2.6)$ & $1.32(1.08$ to 1.61$)$ \\
\hline Injury - accidental, by other means (TN8) & $1516(13.3)$ & $1228(10.4)$ & $1.32(1.18$ to 1.46$)$ \\
\hline Other urethral and urinary tract disorders (K19) & $716(6.3)$ & $563(4.8)$ & 1.31 (1.13 to 1.52$)$ \\
\hline Other cellulitis and abscess (MO3) & $297(2.6)$ & $233(2.0)$ & 1.31 (1.04 to 1.64$)$ \\
\hline Candidiasis (AB2) & $259(2.3)$ & $206(1.7)$ & 1.30 (1.02 to 1.66$)$ \\
\hline Heart failure (G58) & $542(4.8)$ & $432(3.7)$ & 1.28 (1.07 to 1.52 ) \\
\hline Head and neck symptoms (R04) & $308(2.7)$ & $246(2.1)$ & $1.28(1.02$ to 1.60$)$ \\
\hline Disorders of conjunctiva (F4C) & $667(5.9)$ & $559(4.7)$ & 1.24 (1.06 to 1.44$)$ \\
\hline General symptoms (ROO) & 858 (7.5) & $713(6.1)$ & 1.24 (1.09 to 1.42$)$ \\
\hline Other abdominal and pelvic symptoms (R09) & 440 (3.9) & $369(3.1)$ & 1.23 (1.02 to 1.48$)$ \\
\hline III-defined intestinal tract infections (A08) & 391 (3.4) & $329(2.8)$ & 1.22 (1.00 to 1.48$)$ \\
\hline Respiratory system and chest symptoms (RO6) & $710(6.2)$ & $604(5.1)$ & $1.22(1.05$ to 1.41$)$ \\
\hline Other acute upper respiratory infections ( $\mathrm{HO}$ ) & $574(5.0)$ & $487(4.1)$ & 1.21 (1.03 to 1.43 ) \\
\hline Neurotic disorders (E2O) & $810(7.1)$ & $706(6.0)$ & 1.18 (1.03 to 1.36$)$ \\
\hline Acute bronchitis and bronchiolitis ( $\mathrm{HO}$ ) & 1705 (15.0) & $1565(13.3)$ & 1.13 (1.02 to 1.24$)$ \\
\hline Senile or pre-senile organic psychosis (EOO) & $62(0.5)$ & $94(0.8)$ & $0.65(0.43$ to 1.00$) \dagger$ \\
\hline
\end{tabular}

*Adjusted for age, sex, and social class; non-OA group is reference group, all statistically significant at $1 \%$ level; tresults (not shown) which were significant at $1 \%$ level when adjusted for age, sex, social class, and categories of morbidity counts as defined by number of specific disease groups each subject had consulted for in the study year; non-OA group is the reference group.

selectivity of what people might choose to present to their general practitioners, although it is likely that the most significant morbidities were represented.

The patients' beliefs, attitudes, and psychosocial background may also influence the clinical presentation to general practice, and therefore the records of their health service contact relate to a wide range of problems. Examination of all recorded consultations according to the Read codes or "labels" that were used in a 12 month period gives insight into the nature of these presentations. Our study has suggested a broad picture of increased morbidity in patients with OA. Whether such comorbidity is important in itself will need to be examined in further studies to establish whether it has an effect over and above the separate impact of OA and of each individual comorbid condition.

\section{Study implications}

Our study has shown that measuring clinical comorbidity using general practice records offers a detailed insight into the multiple problems that patients present to their general practitioners. Using $\mathrm{OA}$ as the index condition, morbidity counts were higher in patients with clinical OA than in the non-OA population, and this was independent of age, sex, and social class. Furthermore, it has investigated a wide range of problems for which people consult in primary care and indicated that many of them occurred more frequently in patients with OA than in non-OA controls. This included acute as well as chronic problems and musculoskeletal as well as non-musculoskeletal conditions. The main question which this study raises is whether this level of comorbidity significantly adds to the disability or further impairs the health of individual patients and whether such comorbidity is condition specific. Further assessment of the comorbidity issue could contribute to setting clinical priorities, to choosing effective treatments, and to preventing disability among general practice patients with OA. Finally, the study highlights both the use and potential of well organised general practice computer records to study patterns of illness and health care, and to offer a more comprehensive view of a topic such as comorbidity in OA than might be derived from the study of hospital consulters alone.

\section{ACKNOWLEDGEMENTS}

UTK has been supported by a Medical Research Council (UK) Training Fellowship and NHS R\&D funding to Staffordshire Moorlands Primary Care Research Consortium. 


\section{Authors' affiliations}

U T Kadam, K Jordan, P R Croft, Primary Care Sciences Research

Centre, Keele University, Staffordshire ST5 5BG, UK

\section{REFERENCES}

1 Hippisley-Cox J, Pringle M, Crown N, Meal A, Wynn A. Sex inequalities in ischaemic heart disease in general practice: cross-sectional survey. BMJ 2001;322:832-4

2 Morris AD, Boyle DI, MacAlpine R, Emslie-Smith A, Jung RT, Newton RW, et al. The diabetes audit and research in Tayside Scotland (DARTS) study: electronic record linkage to create a diabetes register. BMJ 1997;315:524-8.

3 Feinstein AR. The pre-therapeutic classification of co-morbidity in chronic disease. J Chronic Dis 1970;23:455-68.

4 Schellevis FG, Van der Velden J, Van de Lisdonk E, van Eijk JT, van Weel C. Comorbidity of chronic diseases in general practice. J Clin Epidemiol 1993:46:469-73.

5 Schellevis FG, Van de Lisdonk EH, Van der Velden J, Hoogbergen SH, Van Eijk JT, Van Weel C. Consultation rates and incidence of intercurrent morbidity among patients with chronic disease in general practice. Br J Gen Pract 1994; 44:259-62.

6 Lawrence RC, Hochberg MC, Kelsey JL, McDuffie FC, Medsger TA Jr, Felts WR, et al. Estimates of the prevalence of selected arthritic and musculoskeletal diseases in the United States. J Rheumatol 1989;16:427-41

7 Martin J, Meltzer H, Elliot D. The prevalence of disability among adults. OPCS surveys of disability in general practice (Report 1). London: HMSO, 1988.

8 March LM, Bachmeier CJ. Economics of osteoarthritis: a global perspective. Baillieres Clin Rheumatol 1997;1 1:817-34.

9 Frankel S, Eachus J, Pearson N, Greenwood R, Chan P, Peters TJ, et al. Population requirement for primary hip-replacement surgery: a cross-sectional study. Lancet 1999;353:1304-9.

10 Peat G, McCarney R, Croft P. Knee pain and osteoarthritis in older adults: a review of community burden and current use of primary health care. Ann Rheum Dis 2001;60:91-7.

11 Hungin AP, Kean WF. Nonsteroidal anti-inflammatory drugs: overused or underused in osteoarthritis? Am J Med 2001;110:8-11S.

12 Ettinger WH, Davis MA, Neuhaus JM, Mallon KP. Long-term physical functioning in persons with knee osteoarthritis from NHANES. I: Effects of comorbid medical conditions. J Clin Epidemiol 1994:47:809-15.

13 Office of Population Census and Surveys (OPCS). Morbidity statistics from general practice, Fourth national study 1991-1992. London: HMSO, 1995 (Series MB5 No.3.)

14 Carr-Hill RA, Rice N, Roland M. Socioeconomic determinants of rates of consultation in general practice based on fourth national morbidity survey of general practices. BMJ 1996;312:1008-13.

15 McNiece R, Majeed A. Socioeconomic differences in general practice consultation rates in patients aged 65 and over: prospective cohort study. BMJ 1999:319:26-8.
16 Hansell A, Hollowell J, Nichols T, McNiece R, Strachan D. Use of the General Practice Research Database (GPRD) for respiratory epidemiology: a comparison with the 4th Morbidity Survey in General Practice (MSGP4). Thorax 1999:54:413-19.

17 Office of Population Census and Surveys. Standard occupational classification. Vol 3. Social class and coding methodology. London: HMSO, 1991.

18 NHS Centre for Coding and Classification. Read codes and the terms projects: a brief guide. London: Department of Health, 1993.

19 Statistical Package for the Social Sciences (SPSS). Version 10.0. Chicago: SPSS Inc, 2000

20 Vedsted P, Christensen MB, Sorensen HT, Fink P, Olesen F. Special status consultation for frequent attenders. Who are the candidates? J Public Health Med 2002;24:53-7.

21 Cushnaghan J, Dieppe P. Study of 500 patients with limb joint osteoarthritis. I. Analysis by age, sex, and distribution of symptomatic joint sites. Ann Rheum Dis 1991;50:8-13.

22 Felson DT, Lawrence RC, Dieppe PA, Hirsch R, Helmick CG, Jordan JM, et al. Osteoarthritis: new insights. Part 1: the disease and its risk factors. Ann Intern Med 2000;133:635-46.

23 Slemenda C, Brandt KD, Heilman DK, Mazzuca S, Braunstein EM, Katz BP, et al. Quadriceps weakness and osteoarthritis of the knee. Ann Intern Med 1997; 127:97-104.

24 Hurley MV. The role of muscle weakness in the pathogenesis of osteoarthritis. Rheum Dis Clin North Am 2000;25:283-98.

25 Nevitt MC, Cummings SR, Kidd S, Black D. Risk factors for recurrent nonsyncopal falls. A prospective study. JAMA 1989;261:2663-8.

26 Spector TD, Hochberg MC. Methodological problems in the epidemiological study of osteoarthritis. Ann Rheum Dis 1994;53:143-6.

27 Gabriel SE, Crowson CS, O'Fallon WM. Comorbidity in arthritis. J Rheumatol 1999;26:2475-9.

28 Philbin EF, Groff GD, Ries MD, Miller TE. Cardiovascular fitness and health in patients with end-stage osteoarthritis. Arthritis Rheum 1995;38:799-805.

29 Davis MA, Ettinger WH, Neuhaus JM. Obesity and osteoarthritis of the knee: evidence from the National Health and Nutrition Examination Survey (NHANES I). Semin Arthritis Rheum 1990;20:34-41S.

30 Von Korff M, Simon G. The relationship between pain and depression. Br J Psychiatry 1996;168(suppl): 101-8.

31 Griffin MR. Epidemiology of nonsteroidal anti-inflammatory drug-associated gastrointestinal injury. Am J Med 1998;104:23-9S.

32 Creamer P, Hochberg MC. Osteoarthritis. Lancet 1997;350:503-9.

33 Scaife B, Gill P, Heywood P, Neal R. Socio-economic characteristics of adult frequent attenders in general practice: secondary analysis of data. Fam Pract 2000;17:298-304.

34 McBeth J, Macfarlane GJ, Benjamin S, Silman AJ. Features of somatization predict the onset of chronic widespread pain: results of a large populationbased study. Arthritis Rheum 2001;44:940-6. 